\title{
電気探査学におけるn一層問題の電位式に 含まれる核函数の一般公式に対する補遺*
}

前論文 ${ }^{1}$ において (2.15) で与えられる漸化式の導出 飞際しては, 行列式 $G_{n-1}$ 抒よび $H_{n-1}$ の性質を明ら かにし，しかもその上に， $G_{n}^{\times}$を定義している関係上， 使用した記号は $G_{n-1}^{+}, H_{n-1}^{\prime} ， G_{n}^{\times}$および $G^{\prime \times}$ あるい は $G^{\times \prime} の 4$ 種になり, したがつて漸化式の導出の仕方 は実に煩雑であつた。この久点を除くには, 導入する記 号の数を極力少なくすることである。

ここでは, 行列式を変形することにより, その変形さ れた行列式の形から直ちに漸化式 (2.15) の得られる自 然な方法を提出する。

\section{漸化式の導き方}

まず $G_{n}$ に関する漸化式 (2.15) の導出から咍める。 前論文1)の (1.7) 式で与えられる行列式 $G_{n}$ において 第 $(2 n-4)$ 列の第 $(2 n-3)$, 第 $(2 n-2)$ 行の組成分子を共 に 0 にすることを考える。いま第 $(2 n-3)$ 列および第 $(2 n-2)$ 列に掛けるべき係数をそれぞれ $x, y$ とすれば, 上の条件を満足するためには， $x$ および $y$ は次の連立 1 次方程式の根でなければならない：
正会員 小野寺 清兵 衛**

$$
\left\{\begin{array}{l}
e^{-\lambda h_{n-1}}=x e^{\lambda h_{n-1}+y\left(-e^{-\lambda h_{n-1}}\right)} \\
-e^{-\lambda n_{n-1}}=x e^{\lambda h_{n-1}+y^{\kappa} n-1 e^{-\lambda h_{n-1}}}
\end{array}\right.
$$

これを解けば， $x$ および $y$ は

$$
\left\{\begin{array}{l}
x=-\frac{1-\kappa_{n-1}}{1+\kappa_{n-1}} e^{-2 n_{n-1}} \\
y=-\frac{2}{1+\kappa_{n-1}}
\end{array}\right.
$$

なる形で与えられる。したがつて，われわれは次に述心゙ る操作によつて，初期の目的安達成することができるわ けである。

$G_{n}$ の第 $(2 n-3)$. 列の各組成分子に $\frac{1-\kappa_{n-1}}{1+\kappa_{n-1}} e^{-2 \lambda n_{n-1}}$ を掛けて，それを第 $(2 n-4)$ 列の同位置の組成分子に加 え; さらに第 $(2 n-2)$ 列に $\frac{2}{1+\kappa_{n-1}}$ を掛けて, 第 $(2 n-4)$ 列に加え, 整頓すれば, $G_{n}$ の $(2 n-5,2 n-4)-,(2 n-5$, $2 n-3)-,(2 n-5,2 n-2)-;(2 n-4,2 n-4)-,(2 n-4,2 n$ -3)-, $(2 n-4,2 n-2)-;(2 n-3,2 n-4)-,(2 n-3,2 n-$ $3)-,(2 n-3,2 n-2)-;(2 n-2,2 n-4)-,(2 n-2,2 n-3)$ 一, $(2 n-2,2 n-2)$ 一組成分子は次の上うな配列になる:

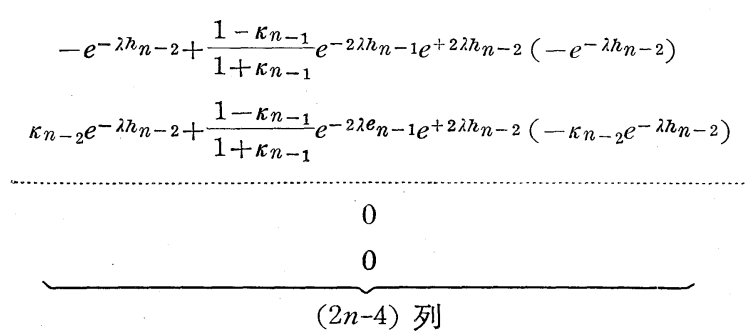

$$
\begin{aligned}
& \text { कえに, } G_{n} \text { は } \\
& \qquad \begin{aligned}
G_{n} & =G_{n-1}(1+\kappa n-1) \\
& +G_{n-1}^{\times}\left(1-\kappa_{n-1}\right) e^{-2 \lambda\left(n_{n-1}-h_{n-2}\right)}
\end{aligned}
\end{aligned}
$$

なる形の漸化式で表わされる。ここに $G_{n-1}$ は行列式 $G_{n}$ に拉いて, 最後の 2 行および 2 列を取去つた行列式 を表わし，一般に $G_{k}$ は $2 k-2$ 次 $(2 \leqq k \leqq n)$ の行列 式である。また $G_{n-1}^{\times}$は $G_{n-1}$ において $\kappa_{n-2}$ の代りに 一片-2 とおいた行列式を表わす。これを記号で書けば

\footnotetext{
* 昭和 35 年 6 月 6 日受理

***元州大学助教授 採鉱学教室

1) 日本鉱業会誌, 76 巻, 861 号, 159 166頁 (昭和 35 年 3 月)

2) Geophysical Prospecting, Vol. III,No. 3, (September, 1955) p. 272 .
}

\begin{tabular}{|ccc}
$-e^{\lambda n_{n-2}}$ & 0 & $(2 n-5)$ 行 \\
$-\kappa_{n-2} e^{\lambda n_{n-2}}$ & 0 & $(2 n-4)$ 行 \\
\hdashline$e^{\lambda n_{n-1}}$ & $-e^{-\lambda n_{n-1}}$ & $(2 n-3)$ 行 \\
$e^{\lambda n_{n-1}}$ & $\kappa n_{n-1} e^{-\lambda n_{n-1}}$ & $(2 n-2)$ 行
\end{tabular}

$(2 n-3)$ 列 $\quad(2 n-2)$ 列

$$
G_{n-1}^{\times}=G_{n-1} \mid \kappa_{n-2} \rightarrow-\kappa_{n-2}
$$

である。ただし，これらの特別形として， $k=2$ のとき は 2 次の行列式の直接計算により

$$
\begin{aligned}
& G_{2}=\left(1-\kappa_{1}\right) e^{-2 \lambda h_{1}}, \\
& G_{2}^{\times}=\left(1+\kappa_{1}\right) e^{-2 \lambda h_{1}}
\end{aligned}
$$

が得られる。

同様汇

$$
\begin{aligned}
& H_{n}=H_{n-1}\left(1+\kappa_{n-1}\right) \\
&+ H_{n-1}^{\times}\left(1-\kappa_{n-1}\right) e^{-2 \lambda\left(n_{n-1}-h_{n-2}\right)} \\
& \text { ここに } \quad H_{n-1}^{\times}=\left.H_{n-1}\right|_{\kappa_{n-2} \rightarrow-\kappa_{n-2}}
\end{aligned}
$$


ただし

$$
\begin{aligned}
& H_{2}=1+\kappa_{1}, \\
& H_{2}^{\times}=1-\kappa_{1} .
\end{aligned}
$$

\section{例}

題

漸化式 (2.15) を用いて， $G_{3}$ および $G_{4}$ を導く。 (2.15) に扔いて $n=3$ とおくと

$$
G_{3}=G_{2}\left(1+\kappa_{2}\right)+G^{\times}\left(1-\kappa_{2}\right) e^{-2 \lambda\left(h_{2}-h_{1}\right)}
$$

功得られる。この式に ( 6 ), ( 7 )を代入すれば上式は

$$
\begin{aligned}
G_{3} & =\left(1-\kappa_{1}\right)\left(1+\kappa_{2}\right) e^{-2 \lambda h_{1}} \\
& +\left(1+\kappa_{1}\right)\left(1-\kappa_{2}\right) e^{-2 \lambda \hbar_{2}}
\end{aligned}
$$

になる。

次に $n=4$ のときは

$$
\begin{aligned}
G_{4} & =G_{3}\left(1+\kappa_{3}\right) \\
& +G_{3}^{\times}\left(1-\kappa_{3}\right) e^{-2 \lambda\left(h_{3}-h_{2}\right)}
\end{aligned}
$$

汇なるが，この式の中の $G_{3}^{\times}$は（12）において $\kappa_{2}$ の代 りに一片と拉いた式，すなわち

$$
\begin{aligned}
& G_{3}^{\times}=\left(1-\kappa_{1}\right)\left(1-\kappa_{2}\right) e^{-2 \lambda h_{1}} \\
& \quad+\left(1+\kappa_{1}\right)\left(1+\kappa_{2}\right) e^{-2 \lambda h_{2}}
\end{aligned}
$$

で与えられる。ゆえに (12)，(14)を(13) に代入すると

$$
\begin{aligned}
G_{4} & =\left(1-\kappa_{1}\right)\left(1+\kappa_{2}\right)\left(1+\kappa_{3}\right) e^{-2 \lambda \hbar_{1}} \\
& +\left(1+\kappa_{1}\right)\left(1-\kappa_{2}\right)\left(1+\kappa_{3}\right) e^{-2 \lambda h_{2}} \\
& +\left(1-\kappa_{1}\right)\left(1-\kappa_{2}\right)\left(1-\kappa_{3}\right) e^{-2 \lambda\left(h_{3}-h_{2}+h_{1}\right)} \\
& +\left(1+\kappa_{1}\right)\left(1+\kappa_{2}\right)\left(1-\kappa_{3}\right) e^{-2 \lambda h_{3}}
\end{aligned}
$$

が得られる。

この方法は前論文 ${ }^{1)}$ の (2・3) で与えられる漸化式一 これは F FATHE の漸化式2) に相当するものであるがによるよりも遙かに便利である。

\section{謝}

辞

この研究をおこなうに当り九州大学教授大野克郎博士 (通信学教室) から懇篤なる指導を受けた。ここに謹ん で謝意を表する。

UDC 550.83 電気探查学における $n$-層問題の電位式に含まれる核函数の一般公式*

76 巻 861 号 $\quad$ p. $159 \sim 166$

昭 和 35 年 3 月

正誤表

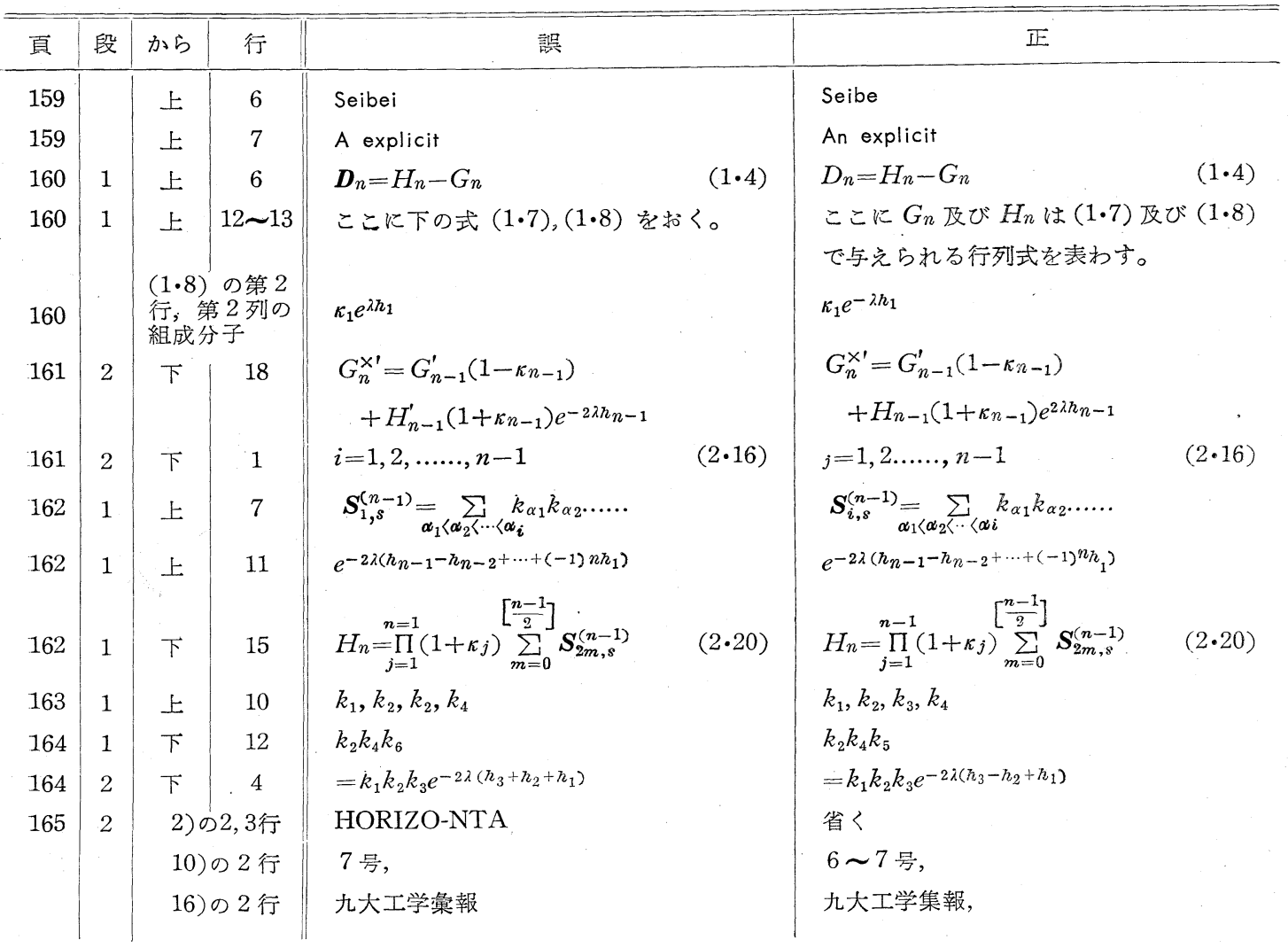

